\title{
Inibição do amadurecimento de abacate com 1-metilciclopropeno(1)
}

\begin{abstract}
Ricardo Alfredo Kluge ${ }^{(2)}$, Angelo Pedro Jacomino ${ }^{(3)}$, Ramon Martinez Ojeda ${ }^{(3)}$ e Auri Brackmann ${ }^{(4)}$
Resumo - O abacate (Persea americana) é um fruto climatérico que apresenta alta taxa respiratória e alta produção de etileno após a colheita, o que o torna altamente perecível. Por isso, o controle do amadurecimento desse fruto é fundamental para o aumento da vida útil de prateleira. Abacates 'Quintal' foram tratados com o bloqueador da ação do etileno 1-metilciclopropeno (1-MCP) nas concentrações de $0,30,90$ e $270 \mathrm{~nL} \mathrm{~L}^{-1}$ durante 12 horas a $24^{\circ} \mathrm{C}$ e armazenados sob condições ambientais $\left(24^{\circ} \mathrm{C}\right)$ por nove dias. Diariamente foram analisadas as variáveis coloração da casca e polpa, firmeza de polpa, porcentagem de frutos maduros (firmeza $\leq 8$ Newtons), porcentagem de podridões, taxa respiratória e produção de etileno. O delineamento experimental foi inteiramente casualizado, em esquema fatorial 4 x 10, com quatro repetições de quatro frutos. O 1-MCP reteve o desenvolvimento da coloração da casca e polpa e proporcionou maior firmeza de polpa e menor incidência de podridão nos frutos. Frutos não tratados apresentaram início de amadurecimento após quatro dias a $24^{\circ} \mathrm{C}$, enquanto nos frutos tratados com $270 \mathrm{~nL} \mathrm{~L}^{-1}$ de 1-MCP o amadurecimento iniciou após sete dias. Frutos tratados com 1-MCP $\left(270 \mathrm{~nL} \mathrm{~L}^{-1}\right)$ apresentaram menor taxa respiratória e menor produção de etileno. Os resultados revelam que a aplicação de 1-MCP em abacates é satisfatória para retardar o amadurecimento dos frutos e aumentar a vida de prateleira.
\end{abstract}

Termos para indexação: Persea americana, produção de etileno, senescência, armazenamento, pós-colheita.

\section{Avocado ripening inhibition by 1-methylciclopropene}

Abstract - Avocados (Persea americana) present high respiratory rate and high ethylene production which make them very vulnerable - and the ripening control of this fruit is fundamental for increasing the shelf life. Avocados 'Quintal' were treated with 1-methylciclopropene (1-MCP) at concentrations of $0,30,90$ and $270 \mathrm{~nL} \mathrm{~L}^{-1}$ for 12 hours at $24^{\circ} \mathrm{C}$ followed by storage at room temperature $\left(24^{\circ} \mathrm{C}\right)$ during nine days. Peel and pulp color, firmness, percentage of ripened fruits (firmness $\leq 8$ Newtons), percentage of decay, respiratory rate and ethylene production were measured daily. The experimental design was a completely randomized with factorial scheme $4 \times 10$ and four replications of four fruits. The application of 1-MCP delayed color development of peel and pulp, maintained higher firmness and reduced fruit decay. Non-treated fruits presented ripening beginning after four days at $24^{\circ} \mathrm{C}$, while fruits treated with 1-MCP $270 \mathrm{~nL} \mathrm{~L}^{-1}$ presented ripening after seven days. The 1-MCP $\left(270 \mathrm{~nL} \mathrm{~L}^{-1}\right)$ reduced fruit respiratory rate and ethylene production. The results permit to infer that 1-MCP application in avocados is satisfactory to reduce ripening process of fruits and to lengthen their shelf life.

Index terms: Persea americana, ethylene production, senescence, storage, postharvest.

\footnotetext{
(1) Aceito para publicação em 29 de outubro de 2001.

(2) Escola Superior de Agricultura Luiz de Queiroz (Esalq), Dep. de Ciências Biológicas, Caixa Postal 9, CEP 13418-900 Piracicaba, SP. Bolsista do CNPq. E-mail rakluge@esalq.usp.br

(3) Esalq, Dep. de Produção Vegetal. Bolsista do CNPq E-mail: jacomino@esalq.usp.br, pmojeda@esalq.usp.br

(4) Universidade Federal de Santa Maria, Dep. de Fitotecnia, CEP 97119-900 Santa Maria, SP. E-mail brackman@creta.ccr.ufsm.br
}

\section{Introdução}

O abacate (Persea americana) é um fruto climatérico que apresenta alta taxa respiratória e produção elevada de etileno após a colheita, o que lhe confere alta perecibilidade sob condições ambientais (Bower \& Cutting, 1988; Kader, 1992). Dada essa característica, o controle do amadurecimento é fundamental para o aumento da vida útil após a colheita, 
visando ao mercado interno e à exportação de frutas. O principal fator que limita o transporte e o tempo de comercialização, e que deprecia a qualidade pós-colheita da fruta, é o amolecimento excessivo decorrente do amadurecimento.

A baixa temperatura tem sido o método de conservação mais comumente empregado na preservação pós-colheita do abacate, cujo tempo máximo de armazenamento é dependente da cultivar e da temperatura utilizada (Bower \& Cutting, 1988). Segundo Gayet et al. (1995), abacates 'Quintal' podem ser armazenados por 14 dias a $7^{\circ} \mathrm{C}$ e $85 \%-90 \%$ de umidade relativa e após esse período, a comercialização pode ser realizada durante três a quatro dias sob temperatura ambiente. Tratamentos complementares como atmosfera modificada ou controlada e aplicações de cálcio favorecem a preservação das frutas (Bower \& Cutting, 1988; Gayet et al., 1995; Meir et al., 1997).

No Brasil, a comercialização do abacate, a varejo, ocorre sem refrigeração, o que torna a aplicação de tecnologia de conservação em temperatura ambiente bastante desejável, pois, a ampliação do período entre a colheita e o amadurecimento pode proporcionar o transporte a longas distâncias e aumento do período de comercialização.

O etileno $\left(\mathrm{C}_{2} \mathrm{H}_{4}\right)$ promove a aceleração do amadurecimento e senescência de frutos climatéricos. Em determinado estádio da maturação, o etileno se liga ao seu receptor na célula, um complexo protéicoenzimático, e desencadeia uma série de eventos que culminam com o amadurecimento e a senescência do fruto (Lelièvre et al., 1997a). Tem sido verificado que a inibição da ligação do etileno ao receptor reduz sua ação, retardando o amadurecimento e a senescência.

Alguns compostos são capazes de bloquear a ligação do etileno ao seu receptor na célula, causando inibição dos efeitos deste hormônio, como é o caso do 2,5-norbornadieno (NBD) e do diazocyclopentadieno (DACP) que retardaram o amadurecimento de maçãs (Blankenship \& Sisler, 1989, 1993; Gong \& Tian, 1998), mas por serem tóxicos não têm sido comercialmente aceitos.

O 1-metilciclopropeno (1-MCP ou $\mathrm{C}_{4} \mathrm{H}_{6}$ ) é um composto volátil recentemente descoberto e que tem demonstrado ser um potente inibidor da ação do etileno (Serek et al., 1995). Embora o 1-MCP seja um gás, ele tem sido formulado como pó, o qual libera o ingrediente ativo quando misturado a uma solução básica ou água. O 1-MCP se liga fortemente ao sítio de ligação do etileno, evitando que sua ligação e ação se procedam.

O 1-MCP retarda a senescência de flores cortadas e plantas envasadas quando aplicado em baixíssimas concentrações (Serek et al., 1994, 1995; Porat et al., 1995; Sisler et al., 1996). Recentes estudos indicaram que o 1-MCP, além de restringir a ação do etileno, pode reduzir sua produção e, com isso, retardar o amadurecimento de muitos frutos climatéricos, como verificado em pêra (Lelièvre et al., 1997b), maçã (Fan et al., 1999), banana (Sisler \& Serek, 1997; Jiang et al., 1999), ameixa (Abdi et al., 1998), tomate (Nakatsuka et al., 1997; Sisler \& Serek, 1997) e damasco (Fan et al., 2000).

O objetivo deste trabalho foi avaliar o efeito inibitório do 1-MCP sobre o amadurecimento e senescência de abacate após a colheita.

\section{Material e Métodos}

O experimento foi realizado no Laboratório de PósColheita do Departamento de Ciências Biológicas da Escola Superior de Agricultura Luiz de Queiroz-USP, Piracicaba, SP. Foram utilizados abacates cultivar Quintal colhidos no Município de Artur Nogueira, SP. A colheita foi realizada no dia 15/8/2000, no início da manhã, e os frutos foram imediatamente transportados à Esalq-USP, em caixas de plástico com proteção em espuma para evitar danos mecânicos. Utilizaram-se frutos sem defeitos, com peso médio de $975 \pm 60 \mathrm{~g}$ e estádio de maturação fisiológica.

Os frutos foram submetidos aos tratamentos com 1-MCP, na formulação pó molhável, contendo $0,14 \%$ de i.a. Foram utilizadas as seguintes concentrações de 1-MCP: $0 \mathrm{~nL} \mathrm{~L}^{-1}, 30 \mathrm{~nL} \mathrm{~L}^{-1}, 90 \mathrm{~nL} \mathrm{~L}^{-1}$ e $270 \mathrm{~nL} \mathrm{~L}^{-1}$. Os frutos foram colocados em câmaras herméticas e expostos ao produto por 12 horas sob temperatura de $24^{\circ} \mathrm{C}$. Quantidades predeterminadas do produto comercial Smart Fresh, na forma de pó, foram colocados em frascos com tampa. Adicionaram-se $20 \mathrm{~mL}$ de água destilada aquecida à temperatura de $50^{\circ} \mathrm{C}$ e agitou-se o frasco até a completa dissolução do produto. Os frascos foram abertos no interior das câmaras, as quais foram fechadas imediatamente para evitar a perda do gás. Após 12 horas de tratamento, as câmaras foram abertas deixando-se os frutos em condições ambientais $\left(24 \pm 2^{\circ} \mathrm{C}\right)$ e procedendo-se à análise diariamente, durante nove dias. 
O delineamento experimental adotado foi o inteiramente casualizado, em esquema fatorial $4 \times 10$. Os fatores estudados foram concentração de 1-MCP (quatro níveis) e tempo de conservação (dez níveis). Foram utilizadas quatro repetições de quatro frutos por parcela útil.

As variáveis determinadas foram: a) coloração da casca e da polpa: através de colorímetro Minolta CR 300, com os resultados expressos em luminosidade ( $\mathrm{L}^{*}$ ) para casca, $\mathrm{e} \mathrm{b}^{*}$ e croma $\left(\mathrm{C}^{*}\right)$ para polpa. Realizaram-se duas leituras da cor da casca em lados opostos da região equatorial do fruto. A cor da polpa foi avaliada por meio de duas leituras na região próxima à cavidade do caroço, após corte transversal do fruto na altura do "pescoço"; b) firmeza de polpa: utilizando-se penetrômetro manual com ponteira plana de $6 \mathrm{~mm}$ de diâmetro, sendo os resultados expressos em Newtons. Foram realizadas quatro leituras em pontos eqüidistantes na região equatorial do fruto, após retirada de uma porção da casca; c) porcentagem de frutos maduros: com firmeza de polpa $\leq 8 \mathrm{~N}$; d) podridões: calculou-se o porcentual de frutos afetados em cada repetição.

Na determinação da respiração e produção de etileno, amostras de frutos foram acondicionadas em câmaras herméticas por duas horas. Posteriormente, coletou-se amostra de $2 \mathrm{~L}$ em recipiente de polietileno, a qual foi enviada ao laboratório do Núcleo de Pesquisa em Pós-colheita da Universidade Federal de Santa Maria, RS. Determinou-se a concentração de etileno em cromatógrafo a gás marca Variam Star 3400CX com coluna Porapak N e detector de ionização de chama (FID). A temperatura da coluna, injetor e detector foi de $90^{\circ} \mathrm{C}, 140^{\circ} \mathrm{C}$ e $200^{\circ} \mathrm{C}$, respectivamente. De cada amostra de gás, foram extraídas duas amostras de $1 \mathrm{~mL}$ com seringa de plástico descartável e injetadas no cromatógrafo. As áreas de pico de etileno foram transformadas em $\mu \mathrm{L} \mathrm{L}^{-1}$ mediante fator de correção obtido pela injeção de um gás padrão com concentração de etileno conhecida. No cálculo da produção de etileno das amostras de frutos, foram levados em consideração o volume da câmara de armazenamento $(60 \mathrm{~L})$, a massa dos frutos e o tempo de acúmulo de etileno. Na determinação da respiração (produção de $\mathrm{CO}_{2}$ ) utilizou-se um analisador de gases $\left(\mathrm{CO}_{2}\right.$ e $\left.\mathrm{O}_{2}\right)$, marca Agri-Datalog. Os gases das amostras foram conduzidos pelo analisador até a estabilização dos valores das concentrações de $\mathrm{CO}_{2}$, expressos em porcentagem. No cálculo da respiração, também foram levados em consideração o volume da câmara de armazenamento, a massa de frutos e o tempo de acúmulo de $\mathrm{CO}_{2}$.

Os modelos lineares em relação às variáveis foram determinados através do programa Sistema de Análise Estatística - SANEST (Zonta \& Machado, 1984).

\section{Resultados e Discussão}

Houve interferência significativa do 1-MCP na coloração da casca dos frutos em relação aos valores obtidos para $\mathrm{L}^{*}$ a partir do sétimo dia de conservação (Figura 1). O L* define a claridade da cor, em que o valor zero representa cor totalmente preta e o 100 totalmente branca (McGuire, 1992). Os frutos tratados com $270 \mathrm{~nL} \mathrm{~L}^{-1}$ mantiveram por mais tempo a coloração verde-escura da casca, principalmente aos sete, oito e nove dias de armazenamento.

O 1-MCP também teve influência sobre a cor da polpa dos frutos, conforme os valores obtidos para $\mathrm{b}^{*}$ e croma (Figura 1). O croma define a intensidade
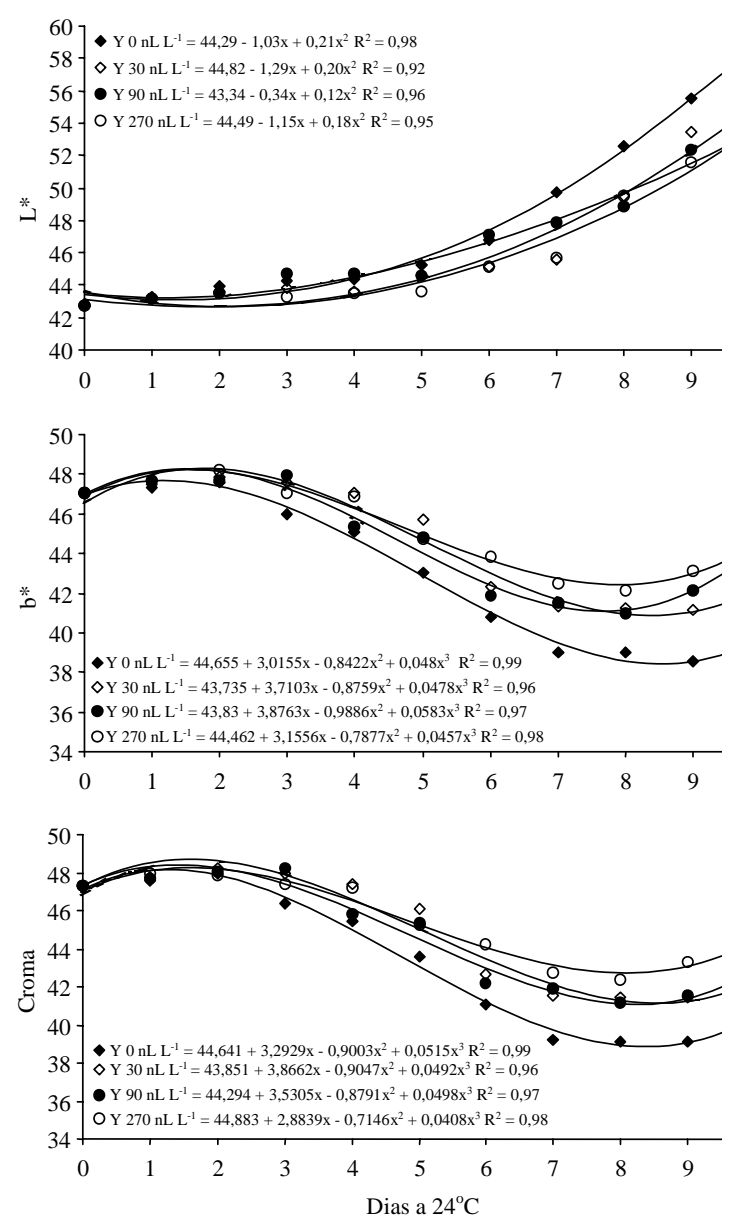

Figura 1. Cor da casca $\left(\mathrm{L}^{*}\right)$ e cor da polpa (b* e croma) em abacates 'Quintal' após tratamento com $0 \mathrm{~nL} \mathrm{~L}^{-1}(\diamond)$; $30 \mathrm{~nL} \mathrm{~L}^{-1}(\diamond) ; 90 \mathrm{~nL} \mathrm{~L}^{-1}(\bullet)$ e $270 \mathrm{~nL} \mathrm{~L}^{-1}(0)$ de 1-MCP e armazenamento a $24^{\circ} \mathrm{C}$.

Pesq. agropec. bras., Brasília, v. 37, n. 7, p. 895-901, jul. 2002 
da cor, assumido valores próximos a zero em relação às cores neutras (cinza) e ao redor de 60 para cores vívidas. Os valores de $b^{*}$ podem variar de -60 quanto as cores totalmente azuis $\mathrm{a}+60$ em relação às cores totalmente amarelas, sendo o valor zero correspondente ao cinza (McGuire, 1992). Durante o amadurecimento, a cor da polpa na região do caroço mudou de amarelo para amarelo-claro (creme), o que pode ser verificado pela redução nos valores de $b^{*} \mathrm{e}$ de croma em todos os tratamentos. De maneira geral, esta alteração foi mais intensa em relação à menor concentração do 1-MCP aplicado nos frutos. A partir do quinto dia de conservação, os valores obtidos no tratamento com $270 \mathrm{~nL} \mathrm{~L}^{-1}$ de 1-MCP foram semelhantes aos do controle.

Os frutos tratados com 1-MCP a $90 \mathrm{~nL} \mathrm{~L}^{-1}$ ou a $270 \mathrm{~nL} \mathrm{~L}^{-1}$ apresentaram menor amolecimento, principalmente a partir do quarto dia de conservação (Figura 2). Frutos tratados com $30 \mathrm{~nL} \mathrm{~L}^{-1}$ de 1 -MCP mantiveram firmeza semelhante à verificada nas maiores concentrações até o quinto dia, mas apresentaram queda brusca no sexto dia, igualando-se ao controle a partir do sétimo dia. Essa concentração parece não ser efetiva em manter a firmeza de polpa dessa variedade. A firmeza da polpa é determinada pela força de coesão entre as pectinas. Com a evolução do amadurecimento do abacate ocorre atuação de enzimas pectinolíticas, particularmente a celulase (endo-1,4- $\beta$-glucanase), a poligalacturonase e a pectinametilesterase, que transformam a pectina insolúvel em solúvel e promovem o amolecimento dos frutos (Bower \& Cutting, 1988; Seymour \& Tucker, 1993). Lelièvre et al. (1997a) comentam que o amolecimento dos frutos é um dos processos do amadurecimento mais sensíveis ao etileno. A maior firmeza dos frutos tratados com as maiores concentrações de 1-MCP está provavelmente associada à redução da atividade das enzimas pectinolíticas, induzida pela menor ação do etileno. Resultados similares foram obtidos com maçã (Fan et al., 1999) e banana (Jiang et al., 1999).

Verificou-se efeito do 1-MCP sobre a porcentagem de frutos maduros (firmeza $\leq 8 \mathrm{~N}$ )(Figura 2). Nas parcelas sem tratamentos detectou-se os primeiros frutos maduros no quarto dia após o início do experimento e $100 \%$ no sétimo dia. Com $270 \mathrm{~nL} \mathrm{~L}^{-1}$ de 1-MCP, os primeiros frutos amadureceram no sé- timo dia e ao final do experimento (nono dia) apenas $62,5 \%$ dos frutos estavam maduros, o que demonstra o potente efeito inibitório do 1-MCP sobre o amadurecimento.

O efeito do 1-MCP sobre porcentagem de frutos com podridões no oitavo e nono dia de armazenamento foi significativo, mostrando que houve maior porcentual de podridão no controle do que nos frutos tratados com 1-MCP (Figura 2). As podridões observadas, que iniciaram em locais com pequenos danos mecânicos ocasionados pela colheita, principalmente na região do pedúnculo, fo-
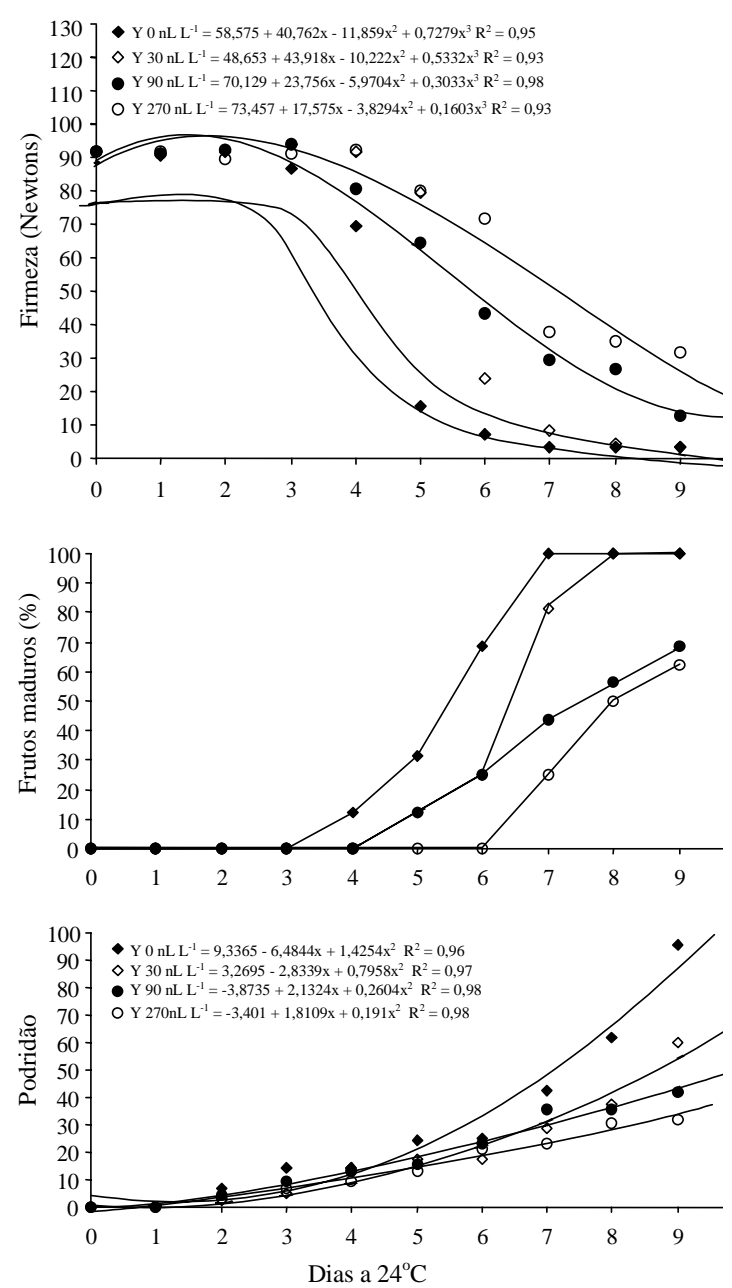

Figura 2. Firmeza de polpa, porcentagem de frutos maduros e porcentagem de podridões em abacates 'Quintal' após tratamento com $0 \mathrm{~nL} \mathrm{~L}^{-1}(\diamond) ; 30 \mathrm{~nL} \mathrm{~L}^{-1}(\diamond) ; 90 \mathrm{~nL} \mathrm{~L}^{-1}$ (๑) e $270 \mathrm{~nL} \mathrm{~L}^{-1}(\mathrm{O})$ de 1 -MCP e armazenamento a $24^{\circ} \mathrm{C}$. 
ram ocasionadas por fungos do gênero Rhizopus, cujo ataque pode ser minimizado a partir da manutenção de parte do pedúnculo e tratamento com fungicida específico após a colheita. Ocorreu também incidência de podridão causada por fungos do gênero Colletotrichum, porém, neste caso, somente nos frutos que atingiram o amadurecimento.

A taxa respiratória (TR) foi influenciada pelos fatores tempo e quantidade de $\mathrm{CO}_{2}$ liberado (Figura 3). Nos frutos não tratados e nos tratados com 30 e $90 \mathrm{~nL} \mathrm{~L}^{-1} \mathrm{o}$ aumento da respiração iniciou no terceiro dia e apresentou pico no sexto dia. Com $270 \mathrm{~nL} \mathrm{~L}^{-1}$, a ascensão climatérica teve início no sexto dia, com pico no sétimo dia. Nesse tratamento, o pico de produção de $\mathrm{CO}_{2}$ teve magnitude menor do que o observado no pico dos demais tratamentos. A redução da TR em frutos tratados com 1-MCP também foi constatada por Fan et al. $(1999,2000)$ e Jiang et al. (1999).

Quanto à produção de etileno, os frutos não tratados e os tratados com $30 \mathrm{~nL} \mathrm{~L}^{-1}$ apresentaram pico de produção no sexto dia (Figura 3). Com $270 \mathrm{~nL} \mathrm{~L}^{-1}$
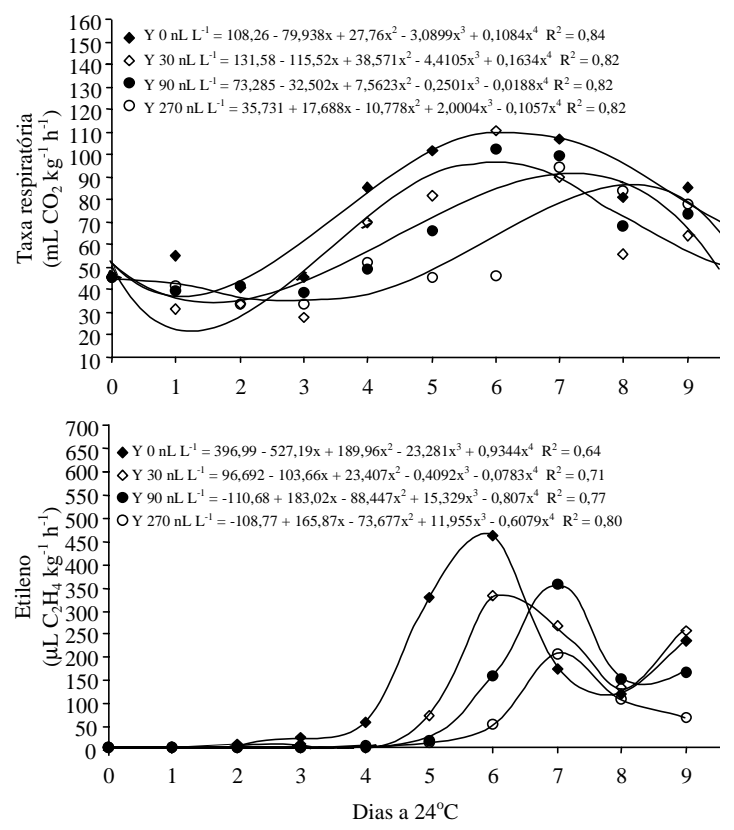

Figura 3. Taxa respiratória e produção de etileno em abacates 'Quintal' após tratamento com $0 \mathrm{~nL} \mathrm{~L}^{-1}(\diamond)$; $30 \mathrm{~nL} \mathrm{~L}^{-1}(\diamond) ; 90 \mathrm{~nL} \mathrm{~L}^{-1}(\bullet)$ e $270 \mathrm{~nL} \mathrm{~L}^{-1}(\mathrm{O})$ de 1-MCP e armazenamento a $24^{\circ} \mathrm{C}$. e $90 \mathrm{~nL} \mathrm{~L}$-1, o pico de produção de etileno ocorreu no sétimo dia, sendo a menor produção observada com a maior concentração de 1-MCP. A menor produção de etileno em frutos tratados com 1-MCP deve-se ao efeito desse regulador em retardar a ação do etileno. A atuação do etileno induz a síntese de mRNA e proteínas (Abeles et al., 1997) e, uma vez restringida sua ação, menor quantidade de ACC oxidase é produzida para reagir com o ácido amino-ciclopropanocarboxílico (ACC) e formar etileno. Desta forma, a menor produção de etileno autocatalítico pode ser considerada um efeito indireto do 1-MCP. A redução na produção de etileno em frutos tratados com 1-MCP também foi observada por Fan et al. (1999, 2000) e Jiang et al. (1999).

A firmeza da polpa foi considerado o principal fator a influenciar a vida útil de prateleira dos frutos deste experimento. Assim, as parcelas não tratadas apresentaram frutos maduros a partir do quarto dia do início do experimento, enquanto aquelas tratadas com $270 \mathrm{~nL} \mathrm{~L}^{-1}$ de 1-MCP somente amadureceram a partir do sétimo dia. Os tratamentos controle e com $30 \mathrm{~nL} \mathrm{~L}^{-1}$ apresentaram $100 \%$ dos frutos maduros no sétimo e oitavo dia após o tratamento, respectivamente. Ao final do experimento (nove dias), os tratamentos 90 e $270 \mathrm{~nL} \mathrm{~L}^{-1}$ apresentaram 68,75\% e 62,50\% de frutos maduros, respectivamente. Essa retenção no amadurecimento é decorrente da capacidade do 1-MCP em inibir a ação do etileno nos tecidos e com isso promover menor produção e atividade de enzimas que degradam a parede celular e amolecem os tecidos.

O aumento no período de conservação de abacate sob condições ambientais, mesmo que por poucos dias, é importante, considerando-se a necessidade de ampliar o período de comercialização e possibilitar o transporte dos frutos a maiores distâncias. Além disso, para variedades de meia-estação, como a Quintal, é vantajoso o armazenamento por serem preferidas no mercado em relação às variedades tardias. O 1-MCP é capaz de retardar o amadurecimento do abacate, provavelmente por bloquear a ligação do etileno ao seu sítio receptor e impedir a sua ação, conforme sugerido por Sisler \& Serek (1997). O fato de o 1-MCP ser um gás, não ser tóxico, não ter odor desagradável e poder ser utilizado em baixas concentrações o credencia para uso comercial. 


\section{Conclusões}

1. O 1-metilciclopropeno (1-MCP) retarda o amadurecimento e prolonga a vida de prateleira de abacates cv. Quintal.

2. As melhores concentrações de 1-MCP para esta cultivar situam-se entre 90 e $270 \mathrm{~nL} \mathrm{~L}^{-1}$.

\section{Referências}

ABDI, N.; McGLASSON, W. B.; HOLFORD, P.; WILLIAMS, M.; MIZRAHI, Y. Responses of climacteric and suppressed-climacteric plums to treatment with propylene and 1-methylcyclopropene. Postharvest Biology and Technology, Wageningen, v. 14, p. 29-39, 1998.

ABELES, F. B.; MORGAN, P. W.; SALTVEIT, M. E. Ethylene in plant biology. 2. ed. San Diego: Academic, 1997. $414 \mathrm{p}$.

BLANKENSHIP, S. M.; SISLER, E. C. 2,5-norbornadiene retards apple softening. HortScience, Alexandria, v. 24, p. 313-314, 1989.

BLANKENSHIP, S. M.; SISLER, E. C. Response of apples to diazocyclopentadiene inhibition of ethylene binding. Postharvest Biology and Technology, Wageningen, v. 3, p. 95-101, 1993.

BOWER, J.; CUTTING, J. G. Avocado fruit development and ripening physiology. Horticultural Review, London, v. 10 , p. $229-271,1988$

FAN, X.; ARGENTA, L.; MATTHEIS, J. P. Inhibition of ethylene action by 1-methylcyclopropene prolongs storage life of apricots. Portharvest Biology and Technology, Wageningen, v. 20, p. 135-142, 2000.

FAN, X.; BLANKENSHIP, S. M.; MATTHEIS, J. P. 1-methylcyclopropene inhibits apple ripening. Journal of the American Society for Horticultural Science, Alexandria, v. 124, p. 690-695, 1999.

GAYET, J. P.; BLEINROTH, E. W.; MATALLO, M.; GARCIA, E. E. C.; GARCIA, A. E.; ARDITO, E. F. G.; BORDIN, M. R. Abacate para exportação: procedimentos de colheita e pós-colheita. Brasília: Embrapa-SPI, 1995. 37 p. (Publicações técnicas, 15).

GONG, Y.; TIAN, M. S. Inhibitory effect of diazocyclopentadiene on the development of superficial scald in 'Granny Smith' apples. Plant Growth Regulation, Dordrecht, v. 26, p. 117-121, 1998.
JIANG, Y.; JOYCE, D. C.; MACNISH, A. J. Extension of the shelf life of banana fruit by 1-methylcyclopropene in combination with polyethylene bags. Postharvest Biology and Technology, Wageningen, v. 16, p. 187-193, 1999.

KADER, A. A. Postharvest technology of horticultural crops. Oakland: University of California, 1992. 296 p.

LELIÈVRE, J. M.; LATCHÉ, A.; JONES, B.; BOUZAYEN, M.; PECH, J. C. Ethylene and fruit ripening. Physiologia Plantarum, Lund, v. 101, p. 727-739, 1997a.

LELIÈVRE, J. M.; TICHIT, L.; DAO, P.; FILLION, L.; NAM, Y. W.; PECH, J. C.; LATCHÉ, A. Effects of chilling on the expression of ethylene biosynthetic genes in PasseCrassane pear (Pyrus communis L.) fruits. Plant Molecular Biology, Dordrecht, v. 33, p. 847-855, 1997b.

McGUIRE, R. G. Reporting of objective color measurements. HortScience, Alexandria, v. 27, p. 12541255, 1992.

MEIR, S.; NAIMAN, D.; AKERMAN, M.; HYMAN, J. Y.; ZAUBERMAN, G.; FUCHS, Y. Prolonged storage of 'Hass' avocado fruit using modified atmosphere packaging. Postharvest Biology and Technology, Wageningen, v. 12, n. 1, p. 51-60, 1997.

NAKATSUKA, A.; SHIOMI, S.; KUBO, Y.; INABA, A. Expression and internal feedback regulation of ACC synthase and ACC oxidase genes in ripening tomato fruit. Plant and Cell Physiology, Kyoto, v. 38, p. 1103-1110, 1997.

PORAT, R.; HALEVY, A. H.; SEREK, M.; BOROCHOV, A. An increase in ethylene sensitivity following pollination is the initial event triggering an increase in ethylene production and enhanced senescence of Phalaenopsis orchid flowers. Physiologia Plantarum, Lund, v. 88, p. 243250, 1995.

SEREK, M.; SISLER, E. C.; REID, M. S. A volatile ethylene inhibitor improves the postharvest life of potted roses. Journal of the American Society for Horticultural Science, Alexandria, v. 119, p. 572-577, 1994.

SEREK, M.; SISLER, E. C.; REID, M. S. 1-Methylcyclopropene, a novel gaseous inhibitor of ethylene action, improves the life of fruit, cut flowers and potted plants. Acta Horticulturae, Leuven, n. 394, p. $337-$ 345, 1995. 
SEYMOUR, G. B.; TUCKER, G. A. Avocado. In: SEYMOUR, G. B.; TAYLOR, J. E.; TUCKER, G. A. (Ed.). Biochemistry of fruit ripening. London: Chapman \& Hall, 1993. p. 53-81.

SISLER, E. C.; SEREK, M. Inhibitors of ethylene responses in plants at the receptors level: recent developments. Physiologia Plantarum, Lund, v. 100, p. 577-582, 1997.
SISLER, E. C.; SEREK, M.; DUPILLE, E. Comparison of cyclopropene, 1-methylcyclopropene, and 3,3-dimethylcyclopropene as ethylene antagonists in plants. Plant Growth Regulation, Dordrecht, v. 18, p. 169-174, 1996.

ZONTA, E. P.; MACHADO, A. A. Sistema de análise estatística para microcomputadores - SANEST (software). Pelotas: Ufpel, 1984. 109 p. 